\title{
Effectiveness of Family Function in Quality of Life in Elderly Patients: An Evidence-Based Case Report
}

\author{
Muhammad Sobri Maulana ${ }^{1}$ \\ 1) Medical Clinical Program, Faculty of Medicine, Universitas Indonesia \\ *Corresponding author: muhammadsobrimaulana31@gmail.com
}

\begin{abstract}
Background: Geriatric care is an important part of healthcare and is sometimes neglected. Family caregivers figures assume a key role in postponing and potentially forestalling standardization of chronically ill elderly patients. The role of family function in depression has been demonstrated from earlier studies, however, the part of the family function in the life quality of the elderly has not concentrated widely. Objective: To evaluate the connection between family function and quality of life. Methods: Literature searching was conducted through PubMed, Science Direct, and Embase. Critical appraisal using appraisal sheet for the prognosis from Oxford Center for Evidence-Based Medicine in 2011. Results: One article was found with good validity showed that a direct relationship between family function and quality of life is not associated. However, if depression is present it plays as a strong mediator between family function and quality of life. Conclusion: Family function mediated with depression plays an important role in the quality of life in elderly patients.
\end{abstract}

Keywords: elderly patients, geriatric patients, family function, quality of life

\section{INTRODUCTION}

Geriatric care is an important part of healthcare and is sometimes neglected. ${ }^{1}$ Managing a geriatric patient is not the same as treating an ill adult, the term geriatric refers to a patient over 65 years old (in Indonesia is 60) with multipathological disorders and decreases in physiological and cognitive function $(1,2)$. Therefore, geriatric medicine aims to promote health by preventing and treating disease and disabilities comprehensively.

Family caregivers figures assume a key role in postponing and potentially preventing institutionalization of chronically ill elderly patients $(1,3)$. Hence, a good family function would ensure the physical health of elderly patients. The association of mental health and family caregivers are often neglected. Depression is the most well-known mental issue among the older which can show as significant major depression or as minor sadness portrayed by an assortment of burdensome side effects $(1,2,4,5)$. The role of family function in depression has been proven from prior studies, however, the role of family function or family capacity in quality of life (QoL) the elderly patients has not been studied extensively. Therefore, this evidence based clinical report aims to assess whether family function plays a role in QoL and depression. 


\section{METHOD}

The combined inquiry utilizing PUBMED, SCIENCE DIRECT, and EMBASE was led in May 2017 and yielded 4 published studies. Based on the titles, abstract, and duplicates screened, 3 potential articles remained and full-text articles were recovered. The full-text articles were assessed dependent on qualification standards, an aggregate of 1 article was resolved to be qualified incorporation in this survey (Figure 1). The search was done using the phrase "elderly patients AND family function AND quality of life". The inclusion criteria were cohort studies, systematic reviews or meta-analysis, studies using English or Indonesian, adult patients $\geq 65$ years old. Exclusion criteria were studies using other than English or
Indonesian, studies published from 20072017, and adult patients < 65 years old. A search through electronic information bases and manual investigations of reference records was carried out. Full-text articles recovered for additional screening. Articles rejected dependent on titles, digests, and copies.

\section{CLINICAL QUESTION}

Patient: Elderly patient

Indicator: Family function

Comparison: -

Outcome: Quality of life

Type of Question: Prognosis

Clinical Question:

Does family function affect the quality of life in elderly patients?

Table 1. Keywords from Pubmed, Science Direct, Embase

\begin{tabular}{|c|c|c|c|}
\hline Database & Keywords & Hits & Included \\
\hline Pubmed & $\begin{array}{l}\text { ((elderly patients OR geriatric } \\
\text { patients[title]) and family function[title]) } \\
\text { and quality of life) AND ((elderly } \\
\text { patients OR geriatric patients) AND } \\
\text { family function) AND quality of life)) }\end{array}$ & 2 & 1 \\
\hline Science & TITLE-ABSTR-KEY (elderly patient & 1 & 0 \\
\hline Direct & $\begin{array}{l}\text { AND family function AND quality of } \\
\text { life) }\end{array}$ & & \\
\hline Embase & $\begin{array}{l}\text { An elderly patient in Title, Abstract, } \\
\text { Keywords and family function in Title, } \\
\text { Abstract, Keywords quality of life in } \\
\text { Title, Abstract, Keywords }\end{array}$ & 1 & 0 \\
\hline
\end{tabular}

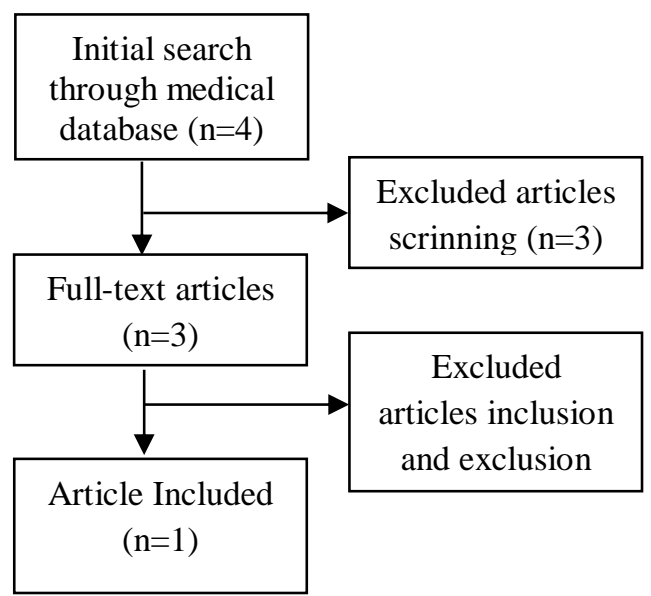

Figure 1. PRISMA diagram of the selection process 
The results obtained from 3 Databases sites were screened by title and abstracts using inclusion and exclusion criteria, filtered double, and checked for those full-text availability. After had read the full text of those articles, we chose a suitable article for our EBCR. Critical appraising of the meta-analysis study was done by consensus of all authors using guidance for prognosis study from Center of Evidence-Based Medicine.

Table 2. VIA Appraisal

\begin{tabular}{|c|c|}
\hline Validity & Canjie et al \\
\hline $\begin{array}{l}\text { Was a defined, } \\
\text { representative } \\
\text { sample of patients } \\
\text { assembled at a } \\
\text { common }\end{array}$ & $\begin{array}{l}\text { This study showed clear diagnostic measurement, inclusion, and } \\
\text { exclusion criteria. The data was obtained from October } 2015 \text { to April } \\
2016 \text {. }\end{array}$ \\
\hline $\begin{array}{l}\text { Follow - up } \\
\text { sufficiently long } \\
\text { and complete? }\end{array}$ & $\begin{array}{l}\text { The patients were not followed up because this is a cross-sectional } \\
\text { study. }\end{array}$ \\
\hline $\begin{array}{l}\text { Were target result } \\
\text { models applied in } \\
\text { a "visual } \\
\text { impaired" design? }\end{array}$ & Blinding was done in this study \\
\hline $\begin{array}{l}\text { The different } \\
\text { prognoses are } \\
\text { identified, was } \\
\text { there an } \\
\text { adjustment for } \\
\text { important } \\
\text { prognostic factors? }\end{array}$ & $\begin{array}{l}\text { This study used multivariate analysis to adjust the sociodemographic } \\
\text { variables such as age, gender, education level, economic conditions, } \\
\text { and marital status. }\end{array}$ \\
\hline $\begin{array}{l}\text { Was there } \\
\text { validation in an } \\
\text { independent group } \\
\text { ("test-set") of } \\
\text { patients? }\end{array}$ & No \\
\hline Importance & Canjie et al \\
\hline $\begin{array}{l}\text { How likely are the } \\
\text { outcomes over } \\
\text { time? }\end{array}$ & $\begin{array}{l}\text { Senior citizens with family dysfunction were } 28.9 \% \text {, with depression } \\
\text { was } 28 \% \text {, the mean quality of life score was } 48.73 \text {. The family } \\
\text { function was negatively correlated with depression and positively } \\
\text { correlated with quality of life. Depression was positively correlated } \\
\text { with quality of life }\end{array}$ \\
\hline $\begin{array}{l}\text { How precise were } \\
\text { the prognostic } \\
\text { estimates? }\end{array}$ & $\begin{array}{l}\text { APGAR score (family function) had an SD of } 2.96 \text { and a range of } 0- \\
10 . \text { GDS had an SD of } 6.13 \text { and a range of } 0-28 . \text { SF-12 (quality of } \\
\text { life) had an SD of } 19 \text { and a range of } 10-94 \text {. }\end{array}$ \\
\hline Applicability & Canjie et al \\
\hline $\begin{array}{l}\text { Similarity } \\
\text { Applicability }\end{array}$ & $\begin{array}{l}\text { No } \\
\text { Yes }\end{array}$ \\
\hline
\end{tabular}




\section{DISCUSSION}

One study was included to evaluate the part family function in mental health and quality of life (QoL). The family caregiver is essential in geriatric patients and could cause depression which whether it is major depression or minor depression $(1,2)$.

However, the effect of family function in QoL is still vague. In this case report, the included study distributed questionnaires to 474 patients to obtain the data needed. GDS, APGAR, SF-12, and CD-RISC were given to the participants and filled out. Other than that, the study also assesses the sociodemographic characteristics (age, gender, marital status, education level, and economic conditions) of the participants. Participants with advanced age (75 years old and over), female, another marital status (single, divorced, and bereaved status), ignorance, and poor financial conditions, have higher unusual family work rate $(\mathrm{p}<0.05)(3,4)$.

Using the APGAR score, it showed that $17.3 \%$ of participants or members had moderate family dysfunctions and $11.6 \%$ had serious or severe family dysfunctions. Nevertheless, the rest $71.1 \%$ of the participants were reported to have a normal family function (4).

Using the GDS, $72.2 \%$ of the participants reported not having depression or depressive symptoms. About $21.5 \%$ were reported to have mild depressive manifestations and $6.3 \%$ had moderate or severe depressive manifestations. The SF12 evaluates the QoL of the participants and was reported that the mean total score was 48.73 (SD: 19.00) $(1,3)$.

The author then analyzed whether the scores and data obtained had correlations or not and if so is it positively or negatively correlated. It is found that family functioning, flexibility, discouragement, depression and Quality of Life had highly significant correlations between each other. Cirtically, depression is significantly negatively fundamentally correlated with family functioning ( $\mathrm{p}<$ 0.01). Meaning that the higher the depression score the lower the family function. Hence, the better or more normal the family is the less likely the geriatric patient to have depression.

The study also analyzed on the multiple mediation model of depression and resilience among quality of life and family functioning. The outcome stated that impact of family function towards quality of life is significant meaning that family function does effect quality of life. In addition, the analysis found that there are mediators from family function to QoL to have an effect, one of which is depression. Resilience is also a mediator in the connection between family function and Quality of Life. However, the magnitude effect of depression as a mediator is larger than resilience $(\mathrm{p}<0.001)(5)$.

Regarding to the patient in this case report, foundings of this study corresponds with the patient. Dysfunction family causes the patient to have depressive symptoms and therefore reduces the QoL. The reason of how depression mediates between functional family and QoL is because old people are more likely to experience positive emotions from functional family and helps to build a stable and effective mental health which promotes personal growth that decrease the incidence of depression. Functional family also seen as a determiner of health, important during later age. Insufficient support could lead to a decrease in life satisfaction and QoL (6). 
Based on the critical appraisal, the included study has good validity and importance. However, the study population is not similar to the patient in this case report. Cultural, religious, spiritual, and traditional differences between the study population and the patient are broad. Nevertheless, the findings of the study are too significant to be ignored, therefore, the course of managing the case report patient could be based on the findings of this study (6).

The writer recommends, based on this evidence-based case report, the family function of the patient resembles the one in the article. Therefore, to manage the depression a better family function must be achieved and maintain for the patient's QoL. Furthermore, further studies should evaluate the role of family function interventions, focusing on depression, which can improve the Quality of Life of the elderly. A study with the Indonesian population should also be done.

\section{RESULT}

Canjie et al show that family functioning, resilience, depression, and Quality of Life had highly significant correlations with each other. An empirical study between relationships shows that depression is significantly negatively correlated with family functioning and all five dimensions (adaption, partnership, growth, resolve, and affection). Otherwise, there are test mediating effects of both depression and resilience between family function and Quality of Life will generate positively correlated with resilience, and all three dimensions (tenacity, strength, optimism). Depression is significantly negatively correlated with the score of resilience and all three dimensions. Depression for a considerable proportion in the relationship between family function and QoL. Depression also plays a mediating role in the relationship between resilience and QoL.

A female patient, 71 years old, came to the clinic with a complaint of back pain 3 days before admission. The pain feels like the patient is being punched and electrocuted, it radiates from the back to the left side of the thigh, VAS showed the pain felt was a score of 7 . The patient said that the pain appeared after she fell in the bathroom. She also complained that her movement was limited due to the pain, she had difficulty to wake up from the bed and must be aid by her son, the pain worsens if the patient walks. Previously she had the same complaint over 1 year ago. Her back has never been x-rayed. From 1 year ago until now she felt no pain. There was no previous back problem before the trauma.

The patient also complained of unable to sleep for 5 years before admission. The patient can close her eyes but cannot fall asleep, if she does she would wake up 2-3 hours later. However, the patient never felt tired of doing activities during the day. Unable to sleep first started when her husband died. In addition, she felt sad because of her family. Her daughter-inlaw often scolded and ignored her, communication between the patient with her in-law and grandchildren is lacking. They only talk if they want something to do with the patient. Her son is rarely at home because he is working and all the house chores are done by the patient. If the patient went for a walk but has not done the house chores, her in-law would call and scolded her. The only caregiver was her son.

On physical examination, it was found that straight leg test $+/+$, leasegue test $<75 /<75$ due to pain, kernig test $<135 /<135$ due to pain. 
Comprehensive geriatric assessment (CGA) showed that the geriatric depression scale (GDS) showed that the patient is depressed. MNA, IADL, ADL Barthel, AMT, and Risk fall in the normal line.

The patient was diagnosed with low back pain, insomnia, depression, and instability. The patient was given meloxicam $2 \times 7.5 \mathrm{mg}$ to subside the pain, neurodex, and consultation with a neurologist.

\section{CONCLUSION}

Results of the study concluded that there is a strong association between family function and depression. Furthermore, depression also acts as a mediator in the connection between family function and Quality of Life.

\section{ACKNOWLEDGMENT}

The comments of the anonymous reviewers and the editor were most helpful in preparing this manuscript. The author is grateful that this manuscript was selected by the Faculty of Medicine Universitas Indonesia.

\section{CONFLICT OF INTEREST}

The author declares that there is no conflict of interest.

\section{REFERENCES}

1. Tesch-Römer C, Motel-Klingebiel A, von Kondratowitz H-J. Importance of family for quality of life of the elderly in a social and cultural comparison. Zeitschrift Gerontol Geriatr [Internet]. 2002 Aug 13;35(4):335-42. Available from:

http://link.springer.com/10.1007/s00 391-002-0107-4

2. Halter J, Ouslander J, Tinetti M, Studenski S, High K, Asthana S. Hazzard's geriatric medicine and gerontology. 6th ed. New York: McGrawhill; 2008.

3. Taqui AM, Itrat A, Qidwai W, Qadri Z. Depression in the elderly: Does family system play a role? A crosssectional study. BMC Psychiatry [Internet]. 2007;7(1):57. Available from: https://doi.org/10.1186/1471 244X-7-57

4. Lebowitz BD, Pearson JL, Schneider LS, Reynolds CF 3rd, Alexopoulos GS, Bruce ML, et al. Diagnosis and treatment of depression in late life. Consensus statement update. JAMA. 1997 Oct;278(14):1186-90.

5. Martire LM, Schulz R, Reynolds CF, Morse JQ, Butters MA, Hinrichsen GA. Impact of close family members on older adults' early response to depression treatment. Psychol Aging [Internet]. 2008;23(2):447-52. Available from: http://doi.apa.org/getdoi.cfm?doi=1 0.1037/0882-7974.23.2.447

6. Lu C, Yuan L, Lin W, Zhou Y, Pan S. Depression and resilience mediates the effect of family function on quality of life of the elderly. Arch Gerontol Geriatr [Internet]. 2017 Jul;71(Juli):34-42. Available from: https://linkinghub.elsevier.com/retri eve/pii/S0167494317301589 